\title{
Strategies of Haze Risk Reduction Using the Tripartite Game Model
}

\author{
Chaoyu Zheng $\mathbb{D}^{1,2}$ Benhong Peng $\mathbb{D}^{1,2}{ }^{1,2}$ XinSheng, ${ }^{2}$ Ehsan Elahi $\mathbb{D}^{3}{ }^{3}$ and Anxia Wan ${ }^{2}$ \\ ${ }^{1}$ Binjiang College, Nanjing University of Information Science and Technology, Wuxi 214105, China \\ ${ }^{2}$ School of Management Science and Engineering, Nanjing University of Information Science and Technology, \\ Nanjing 210044, China \\ ${ }^{3}$ School of Business, Nanjing University of Information Science and Technology, Nanjing 210044, China \\ Correspondence should be addressed to Chaoyu Zheng; zhengcy@nuist.edu.cn, Benhong Peng; 002426@nuist.edu.cn, and \\ Ehsan Elahi; ehsanelahi@nuist.edu.cn
}

Received 18 April 2020; Revised 10 August 2020; Accepted 19 August 2020; Published 14 September 2020

Academic Editor: Dimitri Volchenkov

Copyright $(2020$ Chaoyu Zheng et al. This is an open access article distributed under the Creative Commons Attribution License, which permits unrestricted use, distribution, and reproduction in any medium, provided the original work is properly cited.

\begin{abstract}
Although haze risk management is mainly under government control, willingness of stakeholders is compulsory to determine. Therefore, this study constructs a tripartite game model of government, public, and enterprises and determines the haze risk evolution model considering the initial willingness of stakeholders. Moreover, numerical simulation analysis was also conducted. The results revealed that stakeholders were affected by the change due to initial willingness to participate in and reach the equilibrium at different speeds. It is found that if subsidy coefficient of the government is big, it will reach equilibrium faster. The bigger the penalty coefficient is, the better the pollution reduction effect of pollutant discharge enterprises. It is found that, at the final equilibrium stage, the government will eventually choose to withdraw from supervision, but the speed of withdrawing varies with different regulatory intentions. Study results stress that the government should actively participate in supervision to reduce environmental pollution.
\end{abstract}

\section{Introduction}

In central Asia, haze causes enormous health issues. In the last five decades, haze in China reached the highest level [1]. According to the statistics of the world health organization, in 2018 , about $93 \%$ (1.8 billion children) of the children under the age of 15 breathe haze every day which posed a serious risk to health. In 2016, 600,000 children died of acute lower respiratory tract infection caused by polluted air [2]. Haze became serious issue because it threats society, economy, and health [3]. In order to tackle this problem, the Chinese government has listed the treatment of haze pollution as an important part of ecological civilization construction [4]. China has achieved rapid economic growth; however, less attention has been paid on environmental issues [5].

Studies on haze risk mainly focused on governance risk using evolutionary game method. Evolutionary game theory to the adjustment process of group behavior as a dynamic system describes the behavior of each individual and its relationship with the community and the formation of a mechanism of the individual behavior and group behavior [6]. The theory was used to study the evolution mechanism of haze risk stakeholders which usually involves three groups, the government, the public, and the enterprises. Recently, the research on tripartite game has gradually increased. Che et al. [7] studied the evolution and stability strategies of the government, small loan companies, and small and microenterprises under the government loan risk subsidy policy. Liu and Xia [8] constructed a tripartite game model of stakeholders in the online lending market and analyzed the influence of different strategy choices on the operation of the online lending market. In terms of industry, Zhou et al. [9] analyzed the evolution and stability strategy of the three parties by establishing a tripartite asymmetric evolutionary game model among the government, the banks, 
and the enterprises on the basis of the government rewards and punishments on banks and enterprises at the same time. $\mathrm{Yu}$ and Chen [10] constructed a tripartite model of logistics of the enterprises, the government, and the consumers and analyzed the gradual stability of green innovation diffusion. In addition, the tripartite game has been studied in terms of energy conservation and environmental protection $[11,12]$, carbon pollution reduction $[13,14]$, ecological compensation $[15,16]$, land expropriation [17], take-away waste recovery [18], and commodity quality [19] in combination with stakeholders, environmental supervision evolution strategy, and system dynamics [20, 21].

Most of the existing studies are based on perfect rationality with special emphasis on game equilibrium analysis. It makes it difficult to reveal the mechanism of individual group formation [22]. Because environmental problems have the characteristics of historicity, incomplete information, and strong adaptability of environmental subjects, every participant actually has some rationality. Each player seeks optimization strategy through simulation, learning, and variation. Therefore, researchers have introduced evolutionary game theory into the study of environmental supervision and analyzed the framework of strategic interaction evolution. Zhang and $\mathrm{Li}$ [23] constructed an evolutionary game model for heterogeneous intergovernmental collaborative control of haze and introduced the compensation mechanism and punishment mechanism to analyze the dynamic evolution path of the game system under unconstrained conditions and the evolutionary stability strategy under unconstrained conditions. Xu et al. [24] constructed an evolutionary game model to study urban lowcarbon traffic construction under the background of haze.

Literature focused on haze management but not on haze risk in China. Pan et al. [25] and Jiang and Fang [26] used evolutionary game theory to study the evolutionary game equilibrium between government and enterprise behavior. The evolution of haze risk is mainly a two-party game, with the social public as a variable and rarely as a participant. At the same time, most tripartite game papers consider the problem of how to calculate the stable equilibrium point and the influence of parameter changes on the equilibrium point and seldom pay attention to the initial willingness of stakeholders. It can be seen from the literature retrieval that the existing previous research results have certain reference function for the management of haze risk but there were still some deficiencies. First, most studies of haze risk use the government and enterprises as the main stakeholders but only introduce public behavior as exogenous variables into the game model, and there is no game analysis among public, government, and enterprises. Second, there is no detailed analysis of the way the government participates in the risk of haze, and often only financial support was considered. The mechanism of punishment for enterprises in the real world was ignored. Finally, haze risk studies mainly focused on governance and rarely involved other stakeholders.

Based on the research gaps, this study constructs a tripartite game model including government, public, and enterprises from the perspective of evolutionary game and discusses the gradual stability of haze risk. Considering the influence of the change of stakeholders' willingness on the steady and equilibrium speed of each participant, and integrating the government subsidy and penalty mechanism to dynamically, the study analyzes the impact on pollution reduction intensity of enterprises. Moreover, numerical simulation is used to obtain the evolution path of haze risk under different parameters.

\section{Materials and Methods}

2.1. Construction of the Tripartite Game Model. In order to study the evolutionary game model effectively, in the process of describing the tripartite evolutionary game among the government, public, and enterprises, it is necessary to make some hypothesis.

Suppose there are three stakeholders in the game model. The government (local government), which shall supervise and inspect the situation of enterprise pollution and formulate relevant policies, the public, in order to monitor the government implementation and enterprise pollution reduction efforts, and the enterprises, subject to the supervision of the government and the public, are the implementer of reducing risk of haze.

Brokers' hypothesis was as follows. The purpose of stakeholders is to maximize their own interests. The government is the advocate of environmental protection. The focus of regulatory departments in decision-making is to maximize social and environmental interests, while the goal of the public and enterprises is to maximize individual economy.

Finite rational hypothesis was as follows. This paper discards the traditional game and chose the evolutionary game, mainly because the limited rationality of stakeholders is more in line with the actual situation.

The government has two strategies: "supervise" and "no supervise." The public has two choices for the behavior strategies of government and enterprises: "participation" and "no participation". Similarly, enterprises have two strategies for haze risk: "no pollution" and "pollution."

2.2. Definition of Parameters. According to the model hypothesis, the parameters defined in Table 1 are used in the model considered by the government, public, and enterprises when choosing the strategy. $C_{1}<\varphi P_{1}$ means that the cost of management and control of enterprises is less than that of sewage fines; otherwise, enterprises choose to discharge pollutants. $P_{4}>P_{3}>P_{2}>P_{1}$ is known by definition. $I>C_{5}$ means that the cost of pollution control is higher than the opportunity cost of no pollution. $R>C_{6}$ means that the benefits of public participation are greater than the costs.

2.3. Construction of Payoffs Matrix. The evolution of haze risk can be seen as a result of the dynamic game among government, public, and enterprises. The strategies of government supervision and no supervision, public participation and no participation, and enterprise no pollution and pollution are combined based on the hypothesis of the model. The payoffs matrix of the three parties is shown in Table 2. 
TABLE 1: Definitions of the parameters.

\begin{tabular}{lr}
\hline Parameters & Definitions \\
\hline$\varphi$ & Penalty factor obtained by an enterprise when discharging pollutants \\
$\mathbf{C}_{1}$ & General control cost \\
$\mathbf{C}_{2}$ & Pay additional control costs when the public participate \\
$\mathbf{C}_{3}$ & Corporate pollution causes social losses (environmental pollution, etc.), and the government pays the cost of governance \\
$\mathbf{F}_{1}$ & Government payoffs from enterprises' pollution discharge with the participation of the public \\
$\mathbf{F}_{2}$ & Government payoffs from enterprises' pollution discharge without the participation of the public \\
$\mathbf{F}_{3}$ & Government payoffs from enterprises' no pollution discharge with the participation of the public \\
$\mathbf{F}_{4}$ & Government payoffs from enterprises' no pollution discharge without the participation of the public \\
$\mathbf{I}$ & Enterprise pollution control cost \\
$\mathbf{C}_{4}$ & Reputation cost of enterprise pollution discharge \\
$\omega$ & Government subsidy coefficient when no pollution and government inspection are adopted \\
$\mathbf{C}_{5}$ & Opportunity cost of no pollution policy \\
$\mathbf{P}_{1}$ & Payoffs from pollution of enterprises with public participation \\
$\mathbf{P}_{2}$ & Payoffs from pollution of enterprises without public participation \\
$\mathbf{P}_{3}$ & Payoffs from not pollution of enterprises with public participation \\
$\mathbf{P}_{4}$ & Payoffs from not pollution of enterprises without public participation \\
$\mathbf{R}$ & Proceeds from public participation events \\
$\mathbf{C}_{6}$ & The public supervision costs time, search, etc. \\
$\mathbf{C}_{7}$ & The public do not participate in the discussion of the incident, and potential interests are damaged \\
$\mathbf{x}$ & Probability of government control \\
$\mathbf{y}$ & Probability of the public participation \\
$\mathbf{z}$ & Enterprise pollution probability
\end{tabular}

Note. Condition $\left(C_{1}<\varphi P_{1}, P_{4}>P_{3}>P_{2}>P_{1}, I>C_{5}, R>C_{6}, x, y, z \in[0,1]\right)$.

TABLE 2: Tripartite game matrix of government, public, and enterprise.

\begin{tabular}{|c|c|c|c|c|c|}
\hline \multirow{4}{*}{ Enterprises } & \multicolumn{5}{|c|}{ The government } \\
\hline & \multirow{2}{*}{\multicolumn{2}{|c|}{$\begin{array}{l}\text { Supervision } \mathbf{x} \\
\text { The public }\end{array}$}} & - & \multirow{2}{*}{\multicolumn{2}{|c|}{$\begin{array}{c}\text { No supervision } 1-\mathbf{x} \\
\text { The public }\end{array}$}} \\
\hline & & & - & & \\
\hline & Participation $\mathbf{y}$ & No participation $1-\mathbf{y}$ & - & Participation y & No participation $1-\mathbf{y}$ \\
\hline No pollution $\mathrm{z}$ & $\left(a_{1}, b_{1}, c_{1}\right)$ & $\left(a_{2}, b_{2}, c_{2}\right)$ & - & $\left(a_{3}, b_{3}, c_{3}\right)$ & $\left(a_{4}, b_{4}, c_{4}\right)$ \\
\hline Pollution $1-\mathbf{z}$ & $\left(a_{5}, b_{5}, c_{5}\right)$ & $\left(a_{6}, b_{6}, c_{6}\right)$ & - & $\left(a_{7}, b_{7}, c_{7}\right)$ & $\left(a_{8}, b_{8}, c_{8}\right)$ \\
\hline
\end{tabular}

When the government chooses the supervision strategy, the public chooses the participation strategy, and the enterprises choose the no pollution strategy. The government payoffs are the benefits brought by the no pollution strategy under the public participation $F_{3}$ minus the regulatory cost of the government $C_{1}+C_{2}$ and the green no pollution subsidy $\omega I$ to the enterprises, so the government payoffs are $F_{3}-\omega I-C_{1}-C_{2}$.

The public payoffs are the payoffs $R$ of the participation event minus the supervision cost $C_{6}$ of the participation event, so the public payoffs are $R-C_{6}$, and the payoffs of the same enterprise are $P_{3}+\omega I-I$. Similarly, the game values of other governments, the public, and enterprises can also be obtained.

\section{Evolutionary Stable Analysis}

3.1. Expected Payoffs. In Table 3, we can see the expected payoffs $\left(U_{g 1}, U_{g 2}\right)$ and the average expected payoffs $\overline{U_{g}}$ of the government's choice of the "supervision" strategy and "no supervision" strategy:
TABLE 3: The specific payoffs of government, public, and enterprise.

\begin{tabular}{lccc}
\hline Payoffs & The government & $\begin{array}{c}\text { The } \\
\text { public }\end{array}$ & Enterprises \\
\hline$\left(\mathbf{a}_{1}, \mathbf{b}_{1}, \mathbf{c}_{1}\right)$ & $F_{3}-\omega I-C_{1}-C_{2}$ & $R-C_{6}$ & $P_{3}+\omega I-I$ \\
$\left(\mathbf{a}_{2}, \mathbf{b}_{2}, \mathbf{c}_{2}\right)$ & $F_{4}-\omega I-C_{1}$ & 0 & $P_{4}+\omega I-I$ \\
$\left(\mathbf{a}_{3}, \mathbf{b}_{3}, \mathbf{c}_{3}\right)$ & $F_{3}-C_{2}$ & $R-C_{6}$ & $P_{3}-I$ \\
$\left(\mathbf{a}_{4}, \mathbf{b}_{4}, \mathbf{c}_{4}\right)$ & $F_{4}$ & 0 & $P_{4}-I$ \\
$\left(\mathbf{a}_{5}, \mathbf{b}_{5}, \mathbf{c}_{5}\right)$ & $F_{1}+\varphi P_{1}-C_{1}-C_{2}-C_{3}$ & $R-C_{6}$ & $P_{1}-\varphi P_{1}-C_{4}-C_{5}$ \\
$\left(\mathbf{a}_{6}, \mathbf{b}_{6}, \mathbf{c}_{6}\right)$ & $F_{2}+\varphi P_{1}-C_{1}-C_{3}$ & $-C_{7}$ & $P_{2}-\varphi P_{1}-C_{4}-C_{5}$ \\
$\left(\mathbf{a}_{7}, \mathbf{b}_{7}, \mathbf{c}_{7}\right)$ & $F_{1}-C_{2}-C_{3}$ & $R-C_{6}$ & $P_{1}-C_{5}$ \\
$\left(\mathbf{a}_{8}, \mathbf{b}_{8}, \mathbf{c}_{8}\right)$ & $F_{2}-C_{3}$ & $-C_{7}$ & $P_{2}-C_{5}$ \\
\hline
\end{tabular}

$$
\begin{aligned}
& U_{g 1}=y z a_{1}+(1-y) z a_{2}+y(1-z) a_{5}+(1-y)(1-z) a_{6} \\
& U_{g 2}=y z a_{3}+(1-y) z a_{4}+y(1-z) a_{7}+(1-y)(1-z) a_{8} \\
& \overline{U_{g}}=x U_{g 1}+(1-x) U_{g 2} .
\end{aligned}
$$

In the game, the expected payoffs $U_{p 1}$ of the "participation" strategy, the expected payoffs $U_{p 2}$ of the "no 
participation" strategy, and the average expected payoffs $\overline{U_{p}}$ are given in the following:

$$
\begin{aligned}
& U_{p 1}=x z b_{1}+(1-x) z b_{3}+x(1-z) b_{5}+(1-x)(1-z) b_{7} \\
& U_{p 2}=x z b_{2}+(1-x) z b_{6}+x(1-z) b_{4}+(1-x)(1-z) b_{8} ; \\
& \overline{U_{p}}=y U_{p 1}+(1-y) U_{p 2} .
\end{aligned}
$$

In the game, the expected payoffs $U_{e 1}$ of the "no pollution" strategy, the expected payoffs $U_{e 2}$ of the "pollution" strategy, and the average expected payoffs $\bar{U}_{e}$ are as follows:

$$
\begin{aligned}
U_{e 1} & =x y c_{1}+x(1-y) c_{2}+(1-x) y c_{3}+(1-x)(1-y) c_{4} \\
U_{e 2} & =x y c_{5}+x(1-y) c_{6}+(1-x) y c_{7}+(1-x)(1-y) c_{8} \\
\overline{U_{e}} & =z U_{e 1}+(1-z) U_{e 2} .
\end{aligned}
$$

3.2. Replicated Dynamic Equation Solution. Despite the previous analysis, the government's replication dynamic equation is obtained as follows:

$$
F(x)=\frac{\mathrm{d} x}{\mathrm{~d} t}=x\left(U_{g 1}-\overline{U_{g}}\right)=x(1-x)\left[z\left(-\varphi P_{1}-\omega I\right)-C_{1}+\varphi P_{1}\right] .
$$

The replication dynamic equation of the public is given as follows:

$$
F(y)=\frac{\mathrm{d} y}{\mathrm{~d} t}=y\left(U_{p 1}-\overline{U_{p}}\right)=y(1-y)\left[R-C_{6}-C_{7}\right] .
$$

The replication dynamic equation of enterprise is given as follows:

$$
\begin{aligned}
F(z)= & \frac{\mathrm{d} z}{\mathrm{~d} t}=z\left(U_{e 1}-\overline{U_{e}}\right)=z(1-z)\left[x\left(\varphi P_{1}+C_{4}+\omega I\right)\right. \\
& \left.+y\left(P_{3}-P_{1}-P_{4}+P_{2}\right)+P_{4}-P_{2}+C_{5}-I\right]
\end{aligned}
$$

By combining the previous equations, the dynamic replication system of the government, the public, and the enterprise is given as follows:

$$
\left\{\begin{array}{l}
F(x)=x(1-x)\left[z\left(-\varphi P_{1}-\omega I\right)-C_{1}+\varphi P_{1}\right] \\
F(y)=y(1-y)\left[R-C_{6}-C_{7}\right] \\
F(z)=z(1-z)\left[x\left(\varphi P_{1}+C_{4}+\omega I\right)+y\left(P_{3}-P_{1}-P_{4}+P_{2}\right)+P_{4}-P_{2}+C_{5}-I\right] .
\end{array}\right.
$$

According to Friedman's method, the evolutionary stability strategy (ESS) of differential equation system can be obtained from the local stability analysis of the Jacobian matrix of the system [27]. The Jacobian matrix of the system can be obtained from the previous formula as follows:

$$
J=\left[\begin{array}{ccc}
(1-2 x)\left[z\left(-\varphi P_{1}-\omega I\right)-C_{1}+\varphi P_{1}\right] & 0 & x(1-x)\left(-\varphi P_{1}-\omega I\right) \\
0 & (1-2 y)\left[R-C_{6}-C_{7}\right] & 0 \\
z(1-z)\left(\varphi P_{1}+C_{4}+\omega I\right) & z(1-z)\left(P_{3}-P_{1}-P_{4}-P_{2}\right) & C_{33}
\end{array}\right]
$$

Note that $C_{33}=(1-2 z)\left[x\left(\varphi P_{1}+C_{4}+\omega I\right)+y\right.$ $\left.\left(P_{3}-P_{1}-P_{4}+P_{2}\right)+P_{4}-P_{2}+C_{5}-I\right]$.

If $F(x)=F(y)=F(z)=0$, the local equilibrium points can be obtained as follows: $E_{1}(0,0,0), E_{2}(0,0,1), E_{3}(0,1,0)$, $E_{4}(0,1,1), E_{5}(1,0,0), E_{6}(1,0,1), E_{7}(1,1,0)$, and $E_{8}(1,1,1)$. According to the evolutionary game theory, the equilibrium point satisfying that all eigenvalues of Jacobian matrix are all nontiming is the evolutionary stable strategy (ESS) of the system.

3.3. Stability Analysis of Equilibrium Point. First of all, we analyze the case where the equilibrium point is $E_{0}(0,0,0)$ and the Jacobian matrix is

$$
J_{1}=\left[\begin{array}{ccc}
\varphi P_{1}-C_{1} & 0 & 0 \\
0 & R-C_{6}-C_{7} & 0 \\
0 & 0 & P_{4}-P_{2}+C_{5}-I
\end{array}\right]
$$

It can be seen that the eigenvalue of the Jacobian matrix is $\quad \lambda_{1}=\varphi P_{1}-C_{1}, \lambda_{2}=R-C_{6}-C_{7}, \lambda_{3}=P_{4}-P_{2}+C_{5}-I$. By analogy, eight equilibrium points are, respectively, brought into the Jacobian matrix, and the eigenvalues of the Jacobian matrix corresponding to the equilibrium points can be obtained as shown in Table 4 .

In order to facilitate the analysis of the symbols of the corresponding eigenvalues of different equilibrium points, and without losing generality, assume that $R-C_{6}+C_{7}>0$; 
TABLE 4: Eigenvalues of Jacobian matrix.

\begin{tabular}{|c|c|c|c|}
\hline Equilibrium point & Eigenvalue $\lambda_{1}$ & Eigenvalue $\lambda_{2}$ & Eigenvalue $\lambda_{3}$ \\
\hline $\mathrm{E}_{1}(\mathbf{0}, \mathbf{0}, \mathbf{0})$ & $\varphi P_{1}-C_{1}$ & $R-C_{6}+C_{7}$ & $P_{4}-P_{2}+C_{5}-I$ \\
\hline $\mathrm{E}_{2}(\mathbf{0}, \mathbf{0}, \mathbf{1})$ & $-\omega I-C_{1}$ & $R-C_{6}+C_{7}$ & $-\left(P_{4}-P_{2}+C_{5}-I\right)$ \\
\hline $\mathrm{E}_{3}(\mathbf{0}, \mathbf{1}, \mathbf{0})$ & $\varphi P_{1}-C_{1}$ & $-\left(R-C_{6}+C_{7}\right)$ & $P_{3}-P_{1}+C_{5}-I$ \\
\hline $\mathbf{E}_{4}(0,1,1)$ & $-\omega I-C_{1}$ & $-\left(R-C_{6}+C_{7}\right)$ & $-\left(P_{3}-P_{1}+C_{5}-I\right)$ \\
\hline $\mathrm{E}_{5}(\mathbf{1}, \mathbf{0}, \mathbf{0})$ & $-\left(\varphi P_{1}-C_{1}\right)$ & $R-C_{6}+C_{7}$ & $\varphi P_{1}+C_{4}+\omega I+P_{4}-P_{2}+C_{5}-I$ \\
\hline $\mathrm{E}_{6}(\mathbf{1}, \mathbf{0}, \mathbf{1})$ & $\omega I+C_{1}$ & $R-C_{6}+C_{7}$ & $-\left(\varphi P_{1}+C_{4}+\omega I+P_{4}-P_{2}+C_{5}-I\right)$ \\
\hline $\mathrm{E}_{7}(\mathbf{1}, \mathbf{1}, \mathbf{0})$ & $-\left(\varphi P_{1}-C_{1}\right)$ & $-\left(R-C_{6}+C_{7}\right)$ & $\varphi P_{1}+C_{4}+\omega I+P_{3}-P_{1}+C_{5}-I$ \\
\hline $\mathrm{E}_{8}(1,1,1)$ & $\omega I+C_{1}$ & $-\left(R-C_{6}+C_{7}\right)$ & $-\left(\varphi P_{1}+C_{4}+\omega I+P_{3}-P_{1}+C_{5}-I\right)$ \\
\hline
\end{tabular}

in similar cases, the revenue of green technology of enterprises should be greater than the green cost minus the opportunity cost. That is, $P_{4}-P_{2}>I-C_{5}, P_{3}-P_{1}>I-C_{5}$. The calculation results are shown in Table 5.

\section{Results and Discussion}

4.1. Evaluation of Government, Public, and Enterprise Game. In order to more intuitively explore the gradual and stable evolution track of haze risk stakeholders under different parameter values, numerical simulation method and MATLAB software are used for simulation analysis based on the established evolutionary game model and different government supervision efforts.

Parameter values are $\phi=0.4, \omega=0.2, C_{1}=7, C_{2}=5$, $C_{3}=5, C_{4}=5, C_{5}=5, C_{6}=1, C_{7}=2, R=5, \quad P_{1}=15, P_{2}=$ $20, P_{3}=25$, and $P_{4}=30$. The values of $x_{0}, y_{0}, z_{0}$ are consistent in the model.

4.2. Influence of Initial State on Game Evolution. Figure 1 illustrates that there are obvious differences in the final game results of the tripartite game groups with different initial values. The higher the probability of government regulators adopting the strategy of "no supervision," the higher the probability of the public adopting the strategy of "participation."

There is a stable equilibrium point $(0,1,1)$ for the stakeholders of haze risk; that is, in the long run, without government supervision, the public and enterprises will finally choose the strategies of "participation" and "no pollution," which is not only inevitable, but also the longterm goal of green development in China.

Simulating the impact of the change of initial willingness of the government, the public and enterprises participate in the haze risk on evolution (Figure 2). Suppose that the initial willingness of the government, the public, and the enterprise is the same; that is, $x=y=z$. Figure 2 depicts that when the initial willingness $x, y, z$ changes at the same time, $x$ converges to $0, y, z$ converges to 1 , and the final equilibrium point tends to $(0,1,1)$, which is consistent with the conclusion of Figure 1. The simulation results show that, with the increase of initial willingness $x, y, z$, the speed of $x$ that tends to 0 slows down, $y, z$ that tends to 1 speeds up, and finally the public and enterprises actively participate in the haze risk. During the haze risk period, when the public and enterprises are not willing to participate in the haze risk, the government will reduce the supervision and give full play to
TABLe 5: Equilibrium point stability.

\begin{tabular}{lcccc}
\hline Equilibrium point & $\lambda_{1}$ & $\lambda_{2}$ & $\lambda_{3}$ & Stability \\
\hline $\mathbf{E}_{1}(\mathbf{0}, \mathbf{0}, \mathbf{0})$ & + & + & + & Saddle point \\
$\mathbf{E}_{2}(\mathbf{0}, \mathbf{0}, \mathbf{1})$ & - & + & - & Unstable point \\
$\mathbf{E}_{3}(\mathbf{0}, \mathbf{1}, \mathbf{0})$ & + & - & + & Unstable point \\
$\mathbf{E}_{4}(\mathbf{0}, \mathbf{1}, \mathbf{1})$ & - & - & - & ESS \\
$\mathbf{E}_{5}(\mathbf{1}, \mathbf{0}, \mathbf{0})$ & - & + & + & Unstable point \\
$\mathbf{E}_{6}(\mathbf{1}, \mathbf{0}, \mathbf{1})$ & + & + & - & Unstable point \\
$\mathbf{E}_{7}(\mathbf{1}, \mathbf{1}, \mathbf{0})$ & - & - & + & Unstable point \\
$\mathbf{E}_{8}(\mathbf{1}, \mathbf{1}, \mathbf{1})$ & + & - & - & Unstable point \\
\hline
\end{tabular}

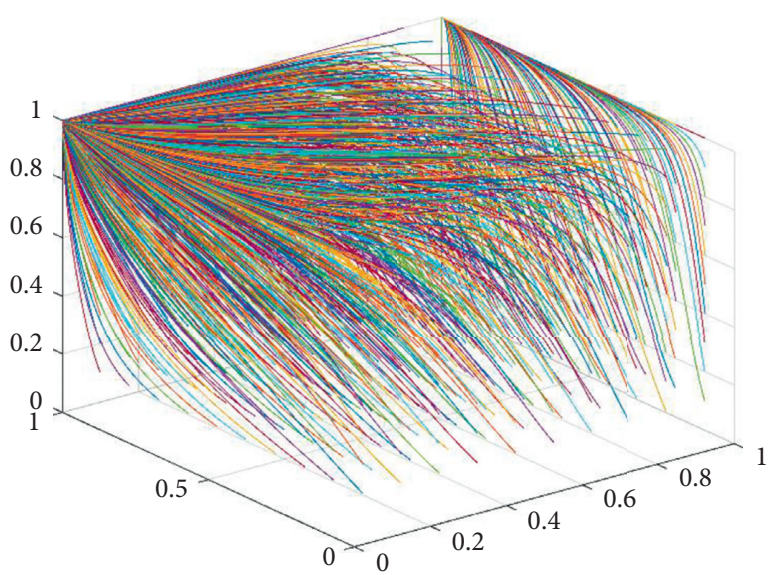

FIGURE 1: Evolution path of tripartite game behavior with different initial values.

the regulatory role of the public on enterprises and the market on enterprises. The higher the pollution reduction willingness of enterprises, the better the effect of pollution reduction. Under the regulatory effect of market mechanism, enterprises will not be able to stand in the market if they are not innovative and positive, so enterprises will actively invest in green pollution reduction [28].

Figure 3 simulates the impact of the change of the initial willingness $x$ on the public and enterprises' participation in the haze risk strategy. Results found that the initial willingness of the public and enterprises to participate is in a medium state. As there is initial willingness of the government to participate in changes continuously, the equilibrium point of the evolution system does not change. The increase of $x$ has no effect on the convergence rate of $y$, which makes the convergence rate of $z$ increase, and the convergence rate of $z$ is greater than $y$. The simulation 


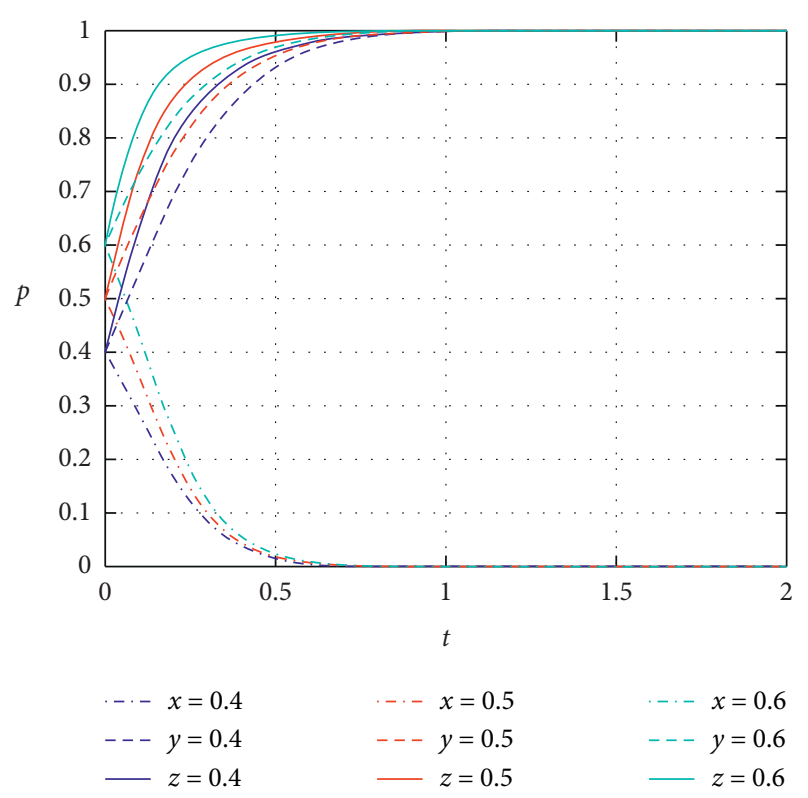

Figure 2: Simultaneous changes of initial willingness to participate $x, y, z$.

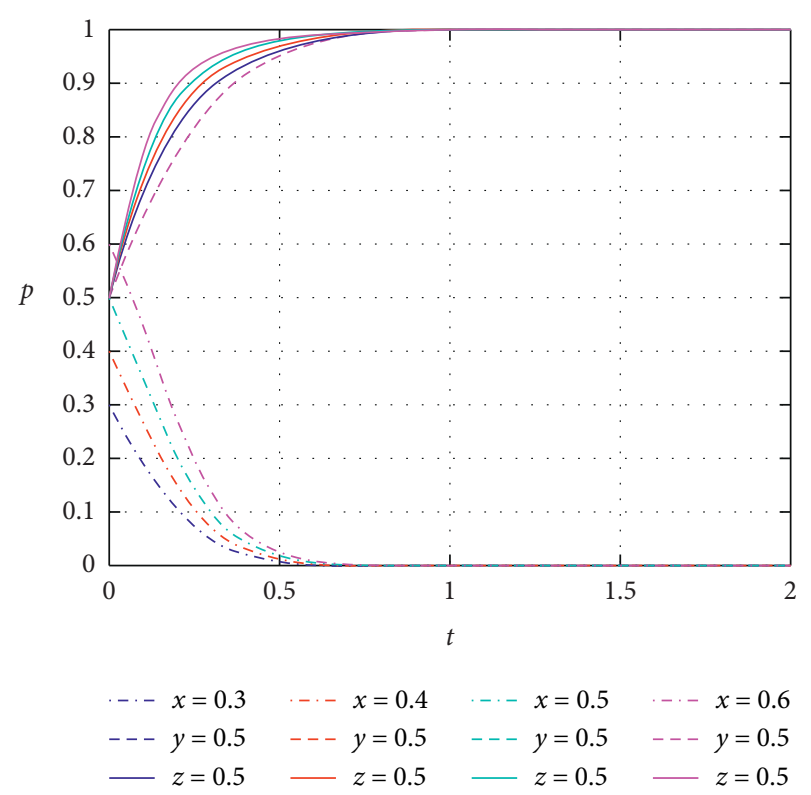

FIGURE 3: Evolution result of change of initial willingness to participate $x$.

results show that, with the increase of the government's initial willingness to participate $x$, the public's willingness to participate remains unchanged, and the enterprises' willingness to participate is significantly affected by the government. The government's pollution penalty and emission reduction subsidy directly affect the enterprises. Therefore, whether enterprises discharge pollutants is greatly affected by the government, while the public pays more attention to whether the haze risk that affects their own interests for a short period of time is not affected by the change of the government's willingness to participate $[29,30]$.

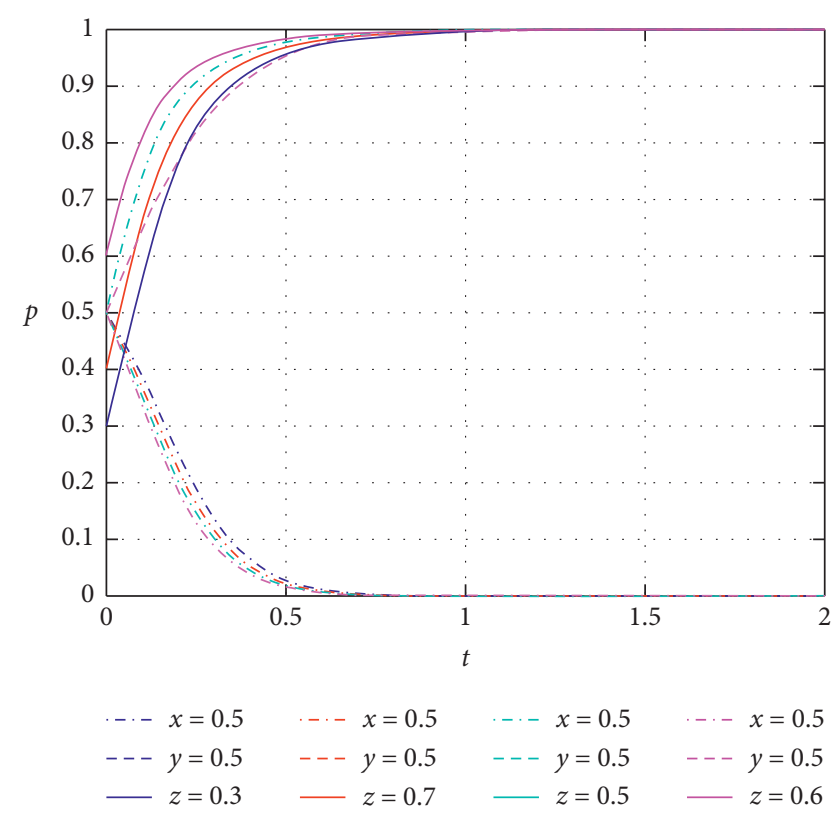

FIgURE 4: Change in initial willingness to participate $z$.

The impact of the change of the initial willingness $z$ on the public and enterprises' participation in the haze risk strategy is simulated in Figure 4. It is found that the initial willingness of government and public participation is in a medium state, the initial willingness of enterprises to participate is constantly changing, and the equilibrium point of the evolution system is unchanged. With the increase of $z$, the convergence rate of $y$ is not affected, while that of $x$ is increased. The simulation results show that as the initial willingness of enterprises to participate $z$ increases, the public's willingness to participate remains unchanged and the government's willingness to participate is enhanced and the government's willingness to participate is less affected by the enterprises. When the enterprise green emission is reduced, the government only provides emission reduction subsidies for the enterprise. The public pays more attention to the impact of haze risk for a short period of time in the future which is not affected by the willingness of enterprises to participate [31].

\subsection{Influence of Government Punishment Coefficient on Game} Evolution. When the punishment coefficient of the government is 0.1 (low), 0.5 (general), and 0.9 (high), the haze risk system finally converges to the $(0,1,1)$ point with the evolution. The government chose the "no supervision" strategy, the public chose the "participation" strategy, and the enterprise chose the "no pollution" policy. The evolution path is shown in Figure 5(a). Figure 5(b) illustrates that no matter how much punishment is imposed, the government will eventually withdraw from supervision. The evolution path is similar under different punishment conditions, which shows that the punishment incentive is not obvious to the government. Panel $\mathrm{C}$ of Figure 5 shows that government punishment has a positive role in promoting enterprises and ultimately making enterprises green innovation to reduce 


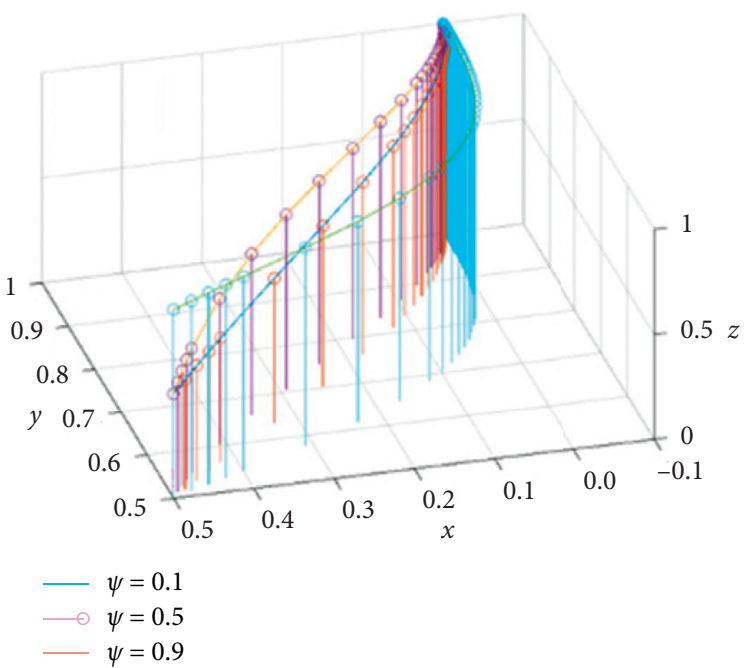

(a)

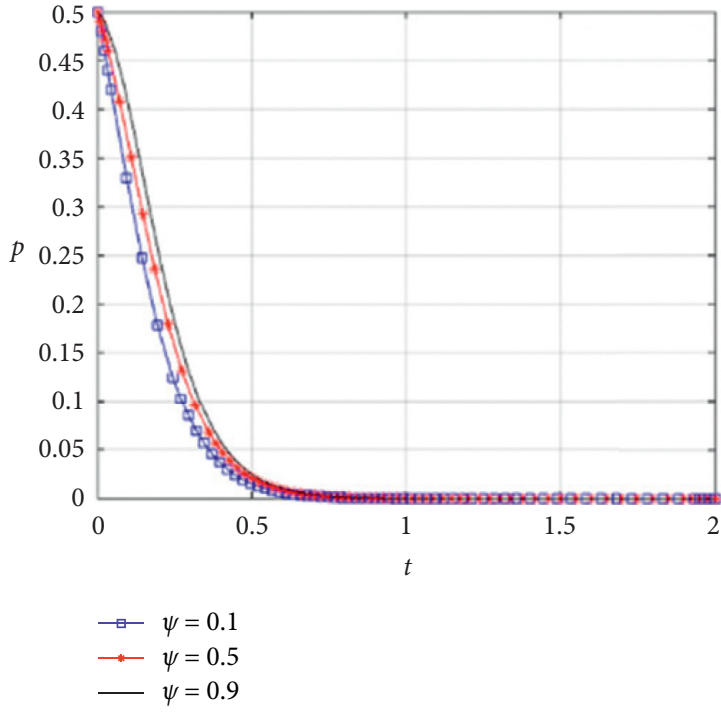

(b)

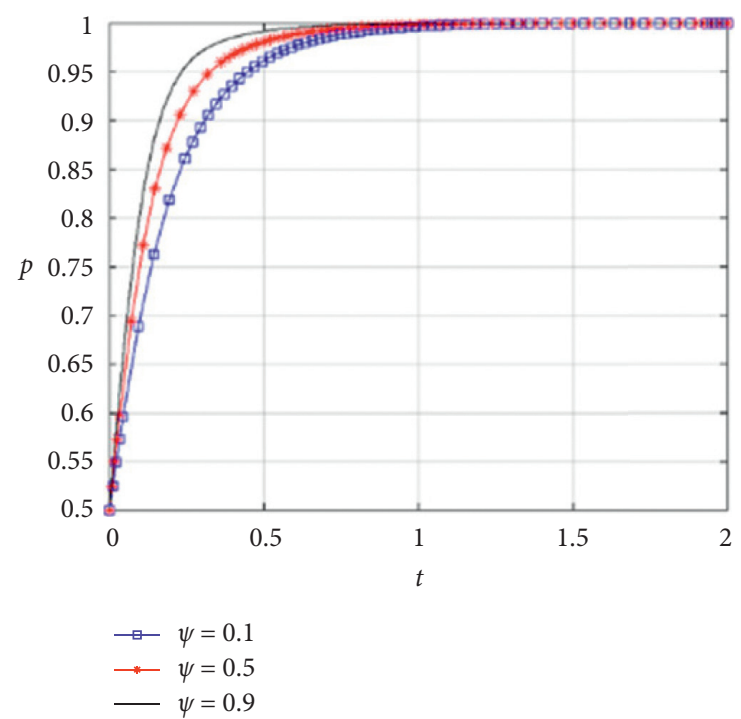

(c)

FIGURE 5: Simulation diagram of evolution path of each subject's behavior under different government punishment coefficients. (a) The evolution of system under different government punishment coefficients. (b) Simulation of evolution path of government behavior under different government punishment coefficients. (c) Simulation of evolution path of enterprise behavior under different government punishment coefficients.

pollution or even not to pollute. It is found that the larger the penalty coefficient, the faster the evolution speed of enterprises' no pollution. This implies that the government's penalty measures will increase the enthusiasm of enterprises for green emission reduction.

For production enterprises, we can see that enterprises should not only meet the interests of consumers but also accept the social responsibility of government supervision from the analysis of the paper and the game model, such as no emission of three wastes. At the same time, enterprises must also obtain profits in order to produce and develop. In the process of finding a balance in the tripartite game, it is better to actively participate in the game system composed of three parties rather than passively accepting supervision, complaints, and paying compensation. Enterprises take the initiative to take corresponding countermeasures in the game, put an end to increasing the emission of three wastes so as to avoid complaints and punishment, and achieve good development under the condition of meeting the government supervision and public demand so as to reduce the penalty coefficient of enterprises by the government. In addition, enterprises to improve the quality of products, under the premise of social responsibility, to produce highquality products with advanced manufacturing technology, will help to get market recognition and obtain good profits.

4.4. Influence of Government Subsidy Coefficient on Game Evolution. When the subsidy coefficient of the government is 0.1 (low), 0.5 (general), and 0.9 (high), the haze risk system 


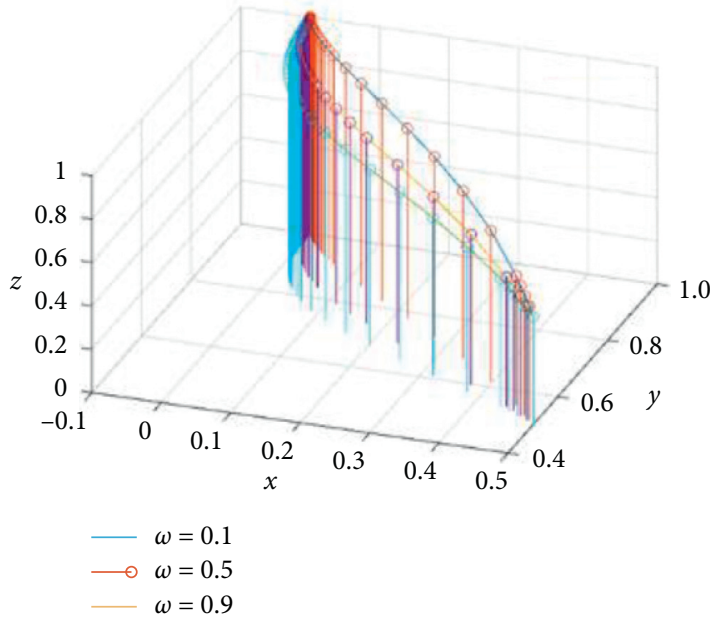

(a)

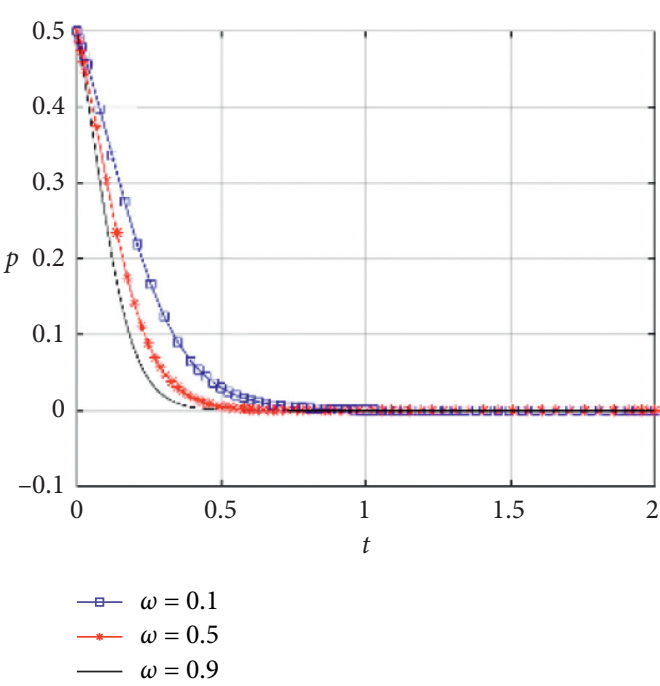

(b)

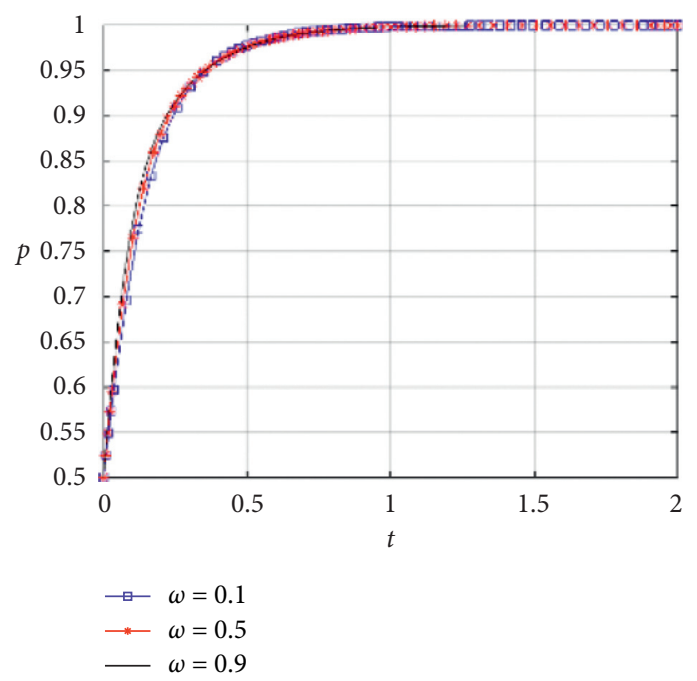

(c)

FIGURE 6: Simulation diagram of evolution path of each subject's behavior under different enterprise subsidies. (a) The evolution of the system under different government punishment coefficients. (b) Simulation of evolution path of government behavior under different government punishment coefficients. (c) Simulation of evolution path of enterprise behavior under different government punishment coefficients.

eventually converges to point $(0,1,1)$ with the evolution. The government chose the "no supervision" strategy, the public chose the "participation" strategy, and the enterprise chose the "no pollution" policy. The evolution path is shown in Figure 6(a). The figure illustrates that when the government subsidies reach a certain level, the enterprises will fully realize green emission reduction and the market will play a regulatory role; when $\omega$ is 0.5 and 0.9 , the larger the government subsidies to the enterprises is, the faster the government evolves to withdraw from supervision, which is because high subsidies will accelerate the power of enterprises to carry out green emission reduction.

However, the evolution track of the government is to supervise first and then withdraw from the supervision when $\omega$ is 0.1 . This is because the effect of low-intensity subsidies on promoting the green emission reduction of pollutant discharge enterprises is not obvious at the early stage of evolution. The government needs to further strengthen the supervision to promote green innovation and emission reduction of enterprises. Panel $\mathrm{C}$ of Figure 5 shows that the evolution paths of emission enterprises under different subsidy coefficients $\omega$ are basically the same. This indicates that the difference in subsidy intensity has no significant impact on the evolution process.

\section{Conclusions and Policy Implications}

5.1. Conclusions. Based on the method of evolutionary game, this paper constructs a tripartite game model of the government regulators, the public, and the group of pollutant discharge enterprises. Considering the speed of the stakeholders reaching the equilibrium point under different 
initial willingness, the stability of the evolution of haze risk was analyzed by integrating the government's subsidy and punishment coefficient and simulated by haze risk under different parameter values. The study found the following.

The government, public, and enterprises have different influences on each other. The public behavior is less affected by the government and enterprises. The impact of the government and enterprises was symmetrical. In the process of haze risk evolution, the better the green emission reduction of pollutant discharge enterprises, the faster the government withdrawal from supervision.

The larger the pollution punishment coefficient is, the faster the enterprises can reach the nonpollution equilibrium. The change of subsidy coefficient has no obvious difference to the stable equilibrium speed of pollutant discharge enterprises. The enterprises guarantee to obtain the same proportion coefficient subsidy under the specified emissions. Without the difference between enterprises, they lack the enthusiasm or innovation and emission reduction.

For the choice of public behavior, the change of government's punishment coefficient and subsidy coefficient has no obvious influence on the evolution. The public is only concerned with the impact of haze risk on themselves for a short period of time. If there is haze in the near future, the public will actively participate in the supervision of public opinion of enterprises and regulatory authorities. On the contrary, if there is no haze, the public usually does not pay attention to the relevant dynamics of environmental supervision department and enterprise emission.

5.2. Policy Implications. Strengthening government supervision, implementing tough pollution investigation, and punishment as well as positive incentive measures for emission reduction behavior can effectively curb the illegal behavior of enterprises. By strengthening the supervision, increasing the penalty parameter $\phi$, and increasing the subsidy parameter $\omega$, the government can reduce the corresponding illegal extra income and improve the enthusiasm of enterprises to implement emission reduction strategies. Under different circumstances, the government can effectively curb the illegal behaviors of enterprises by rational decision-making and strategic choice. Although sewage enterprises play a leading role in the development and innovation process of the country, the construction of green sustainable development system in China at this stage cannot do without the overall planning of the government and the supervision of the third party public. In fact, whether haze governance can be promoted as a whole depends on the guidance and support of the government. As the Third Plenary Session of the 18th CPC Central Committee put forward the goal of establishing a comprehensive and systematic ecological civilization system, it can be expected that China will speed up the revision and improvement of environmental law, air pollution prevention and control law, climate change law, and other relevant laws and regulations, so as to regulate and prevent haze pollution from the source. On the other hand, the government's advocacy and publicity of the concept of green development and the encouragement and reward of public supervision behavior are conducive to enhancing the awareness of green development and environmental protection responsibility of the third-party public, so as to strengthen the supervision of the illegal behavior of pollutant discharge enterprises, promote their energy conservation and emission reduction, and increase investment in science and technology. Therefore, the construction of green environmental protection is the change of the whole social scale. We must rely on the joint efforts of the government, enterprises, and the public, rational decision-making of the government, effective implementation of enterprises, and active supervision of the public, so as to comprehensively promote the development of urban system with low energy consumption, low pollution, high efficiency, and high efficiency.

Regarding to the development of time, the government will finally choose to withdraw from the supervision. If subsidy support for enterprises is higher, the government will withdraw faster from the supervision. This is because enterprises need to control to obtain the government's subsidy under the specified emissions, which slows down the problem of multiple emissions by stealing. If the penalty coefficient is smaller, there would be faster exit from supervision. If the penalty coefficient is higher, there would be greater willingness of government supervision and slower speed of achieving equilibrium and stability.

At the same time, the government should also pay attention to the control of supervision efforts, reasonably plan the investment of supervision cost, avoid the waste of resources caused by unreasonable distribution, prevent excessive administrative participation, and curb the enthusiasm of independent emission reduction. The enterprises should strengthen environmental awareness, increase investment in green emission reduction, and reduce environmental pollution and excessive consumption of resources. The public should start from themselves, participate in the supervision of the government and enterprises, and promote haze risk management.

There are some areas to be improved in this study. Because the simulation was carried out under the different simulation conditions, the effectiveness of the behavioral analysis of the stakeholders in the haze risk evaluation may be biased. In the future, data mining and the intelligent algorithm will be used to conduct an empirical analysis on the big data of haze risk evolution. This paper studies the initial willingness of stakeholders, without considering the factors of stakeholders' psychological willingness. In the future, we may add psychological willingness as a variable into the game model or introduce prospect theory to improve the evolution of haze risk.

\section{Data Availability}

The data used to support the findings of this study are available in this paper.

\section{Conflicts of Interest}

All the authors declare that there are no conflicts of interest. 


\section{Acknowledgments}

The authors are grateful to the case company for permitting and supporting this research. This work was financially supported by Humanities and Social Sciences Research Project of the Ministry of Education (20YJAZH096), HRSA, US DHHS (Grant no. H49MC00068), the National Natural Science Foundation of China (Grant nos. 71263040 and 91546117), the Key Project of National Social and Scientific Fund Program in China (Grant no. 18ZDA052), the Project of National Social and Scientific Fund Program in China (Grant no. 17BGL142), and Open Project of Jiangsu Productivity Society (JSSCL2019B016).

\section{References}

[1] M. Tao, L. Chen, Z. Wang, J. Wang, J. Tao, and X. Wang, "Did the widespread haze pollution over China increase during the last decade? A satellite view from space," Environmental Research Letters, vol. 11, no. 5, Article ID 054019, 2016.

[2] WHO, World Health Statistics 2018: Monitoring health for the SDGs, WHO, Geneva, Switzerland, 2018.

[3] L. Han, Z. Sun, J. He, X. Zhang, Y. Hao, and Y. Zhang, "Does the early haze warning policy in Beijing reflect the associated health risks, even for slight haze?" Atmospheric Environment, vol. 210, pp. 110-119, 2019.

[4] J. Pan, The Development Paradigm of Ecological Civilization, Springer, Berlin, Germany, 2016.

[5] H. Gu, Y. Cao, E. Elahi, S. Jha, and Kumar, "Human health damages related to air pollution in China," Environmental Science and Pollution Research, vol. 26, no. 13, pp. 1-11, 2019.

[6] X. Yin, H. Wang, P. Yin, and H. Zhu, "Agent-based opinion formation modeling in social network: a perspective of social psychology," Physica A: Statistical Mechanics and its Applications, vol. 532, 2019.

[7] T. Che, X. Zhuang, and Y. Su, "Research for risk subsidy mechanism of small loan companies based on evolutionary game in three groups," Forecasting, vol. 36, no. 5, pp. 55-61, 2017, in Chinese.

[8] W. Liu and L. Xia, "Analysis on the behavioral strategy of participants on online lending market based on evolutionary game theory-—a tripartite game perspective," Chinese Journal of Management Science, vol. 26, no. 5, pp. 169-177, 2018, in Chinese.

[9] Y. Zhou, S. Liang, S. Liu, and J. Wang, "The game study of establishing green supply chain from the perspective of green credit," Journal of Management Science and Engineering, vol. 20, no. 12, pp. 87-98, 2017, in Chinese.

[10] L. Yu and Z. Chen, "Research on the green innovation diffusion mechanism of logistics enterprises based on evolutionary game," Operations Research and Management Science, vol. 27, no. 12, pp. 197-203, 2018, in Chinese.

[11] X. Cao and Z. Xing, "The strategy options of energy-saving and environmental protection industry under incomplete information: a tripartite game analysis of government, enterprises and financial institutions," Economic Computation and Economic Cybernetics Studies and Research, vol. 52, no. 3, pp. 189-204, 2018.

[12] L. Zhang, S. Zhou, J. An, and Q. Kang, "Demand-side management optimization in electric vehicles battery swapping service," IEEE Access, vol. 7, pp. 95224-95232, 2019.

[13] H. Shan, J. Yang, and G. Wei, "Industrial symbiosis systems: promoting carbon emission reduction activities,"
International Journal of Environmental Research and Public Health, vol. 16, no. 7, pp. 264-280, 2019.

[14] X. Wu, C. Yaru, X. Yang, and G. Ji, "Finding of urban rainstorm and waterlogging disasters based on microblogging data and the location-routing problem model of urban emergency logistics," Annals of Operations Research, vol. 290, no. 1-2, pp. 1-32, 2018.

[15] X. Wu, Z. Xu, H. Liu, J. Guo, and L. Zhou, "What are the impacts of tropical cyclones on employment? An analysis based on meta-regression," Weather, Climate, and Society, vol. 11, no. 2, pp. 259-275, 2019.

[16] X. Gao, J. Shen, W. He et al., "Multilevel governments' decision-making process and its influencing factors in watershed ecological compensation," Sustainability, vol. 11, no. 7, pp. 1-28, 2019.

[17] Q. Li, H. Bao, Y. Peng, H. Wang, and X. Zhang, "The collective strategies of major stakeholders in land expropriation: a tripartite game analysis of central government, local governments, and land-lost farmers," Sustainability, vol. 9, no. 4, pp. 1-15, 2017.

[18] R. Long, J. Yang, H. Chen, Q. Li, W. Fang, and L. Wang, "Coevolutionary simulation study of multiple stakeholders in the take-out waste recycling industry chain," Journal of Environmental Management, vol. 231, pp. 701-713, 2019.

[19] S. Gu, P. Zhang, and J. Yang, "System dynamics models based on evolutionary game theory for quality supervision among construction stakeholders," Journal of Civil Engineering and Management, vol. 24, no. 4, pp. 318-330, 2018.

[20] W. Duan, C. Li, P. Zhang, and Q. Chang, "Game modeling and policy research on the system dynamics-based tripartite evolution for government environmental regulation," Cluster Computing, vol. 19, no. 4, pp. 2061-2074, 2016.

[21] J. Sheng and M. Webber, "Incentive-compatible payments for watershed services along the eastern route of China's southnorth water transfer project," Ecosystem Services, vol. 25, pp. 213-226, 2017.

[22] M. Sabbaghi, S. Behdad, and J. Zhuang, "Managing consumer behavior toward on-time return of the waste electrical and electronic equipment: a game theoretic approach," International Journal of Production Economics, vol. 182, pp. 545-563, 2016.

[23] M. Zhang and H. Li, "New evolutionary game model of the regional governance of haze pollution in China," Applied Mathematical Modelling, vol. 63, pp. 577-590, 2018.

[24] Y. Xu, X. Zhang, and J. Cao, "Evolutionary game analysis of government regulation and low-carbon transportation behavior under the background of smog," Journal of Systems \& Management, vol. 27, no. 3, pp. 462-469, 2018, in Chinese.

[25] F. Pan, B. Xi, and L. Wang, "Analysis on environmental regulation strategy of local government based on evolutionary game theory," Systems Engineering-Theory \& Practice, vol. 35, no. 6, pp. 1393-1404, 2015, in Chinese.

[26] S. Jiang and P. Fang, "Effect of government subsidies on manufacturers based on green supply chain," Journal of Systems \& Management, vol. 28, no. 3, pp. 594-600, 2019, in Chinese.

[27] S. Feng, S. Tai, C. Sun, and Q. Man, "Numerical study of the performance and emission of a diesel-syngas dual fuel engine," Mathematical Problems in Engineering, vol. 2017, Article ID 1676045, 6 pages, 2017.

[28] J. J. Cronin, J. S. Smith, M. R. Gleim, E. Ramirez, and J. D. Martinez, "Green marketing strategies: an examination of stakeholders and the opportunities they present," Journal of 
the Academy of Marketing Science, vol. 39, no. 1, pp. 158-174, 2011.

[29] A. Macbean, "China's environment: problems and policies," The World Economy, vol. 30, no. 2, pp. 292-307, 2007.

[30] Q. Zhang and R. Crooks, Toward an Environmentally Sustainable Future: Country Environmental Analysis of the People's Republic of China, Asian Development Bank, Mandaluyong, Philippines, 2012.

[31] A. Zhang, L. Zhong, Y. Xu, H. Wang, and L. Dang, “Tourists' perception of haze pollution and the potential impacts on travel: reshaping the features of tourism seasonality in beijing, China," Sustainability, vol. 7, no. 3, pp. 2397-2414, 2015. 